\title{
Longitudinal Study of Social-environmental Predictors of Behavior: Children of Adolescent and Older Mothers Compared
}

Nicole Letourneau

Canadian Research Institute for Social Policy

University of New Brunswick

Fredericton, New Brunswick, Canada

nicoleL@unb.ca

Cara B. Fedick

McGill University

Montreal, Quebec, Canada

J. Douglas Willms

University of New Brunswick

Fredericton, New Brunswick, Canada

Miriam Stewart

University of Alberta

Edmonton, Alberta, Canada

Kelly White

University of New Brunswick

Fredericton, New Brunswick, Canada 
Nicole Letourneau, C. B. Fedick, J. D. Willms, M. Stewart and K. White

\begin{abstract}
Compared to older, more educated mothers, adolescent mothers are more prone to less than optimal parenting interactions with their children. Moreover, adolescents' children are more likely to experience developmental challenges. In this study, effects of social-environmental factors in the first two years of life on children's anxiety and hyperactivity from age 2 to 8 were examined by analyzing Canadian longitudinal data. Initial levels of anxiety and hyperactivity were higher for children of adolescent mothers, and anxiety increased with age for all children. Female children displayed lower initial levels of hyperactivity than males, and females of adolescent mothers showed a steeper decrease in hyperactivity while males of adolescent mothers showed a steeper increase in hyperactivity than their counterparts parented by older mothers. Parenting, social support and other demographic factors were controlled for and the effects of these predictor variables on trajectories of anxiety and hyperactivity are discussed.
\end{abstract}

Key Words: Adolescent and older mothers, hyperactivity, anxiety

\title{
Résumé
}

En comparaison aux mères plus âgées et ayant reçu une meilleure éducation, les mères adolescentes ont tendance à avoir des interactions parentales moins qu'idéales. De plus, les enfants d'adolescentes souffrent plus souvent de troubles de développement. Dans cette étude, les facteurs socioenvironnementaux pendant les deux premières années de vie ainsi que leurs effets sur l'anxiété et l'hyperactivité entre 2 et 8 ans ont été étudiés en analysant des données longitudinales canadiennes. Il a été trouvé que les niveaux initiaux d'anxiété et d'hyperactivité sont plus élevés chez les enfants de mères adolescentes et cette anxiété accroît avec l'âge pour tous les enfants. Le niveau d'hyperactivité chez les filles était moins élevé initialement que chez les garçons et il diminuait rapidement chez les filles de mères adolescentes alors qu'il augmentait rapidement avec l'âge chez les garçons, en comparaison avec les garçons élevés par des mères plus âgées. Le rôle parental, le support social et d'autres facteurs démographiques ont été contrôlés pour l'étude et les effets de ces prédicteurs variables sur les trajectoires d'anxiété et d'hyperactivité sont abordés.

Mots-clés : Mères adolescentes et plus âgées, hyperactivité, anxiété 
Longitudinal Study of Social-environmental Predictors of Behaviour:

Children of Adolescent and Older Mothers Compared

\section{Introduction}

Adolescent mothers and their children frequently live under conditions of high stress, poverty, limited educational opportunities, and family instability (Barbour, Richardson, \& Bubenzer, 1995; Buchholz \& Korn-Bursztyn, 1993; Garrett \& Tidwell, 1999; Klein \& Cordell, 1987; Passino, Whitman, Borkowski, $\&$ et al., 1993). The social context of the mother-child relationship interacts with the personal characteristics of adolescent mothers to influence parenting and subsequent child development (Belsky, 1984; Schellenbach, Whitman, \& Borkowski, 1992). Adolescent mothers' effectiveness may be challenged if their social support is limited (Herrmann, Van Cleve, \& Levison, 1998). Adolescents and their children may live in socially isolated, single-parent, impoverished environments, which may lead to childhood behavioral problems (Halpern, 1993; Osofsky, Hann, \& Peebles, 1993; Osofsky, Wewers, Hann, \& Fick, 1993; Turner, Grindstaff, \& Phillips, 1990; Wakschlag et al., 2000), learning problems (East \& Felice, 1990), poor school performance, and troubled peer relationships (Levine-Coley \& Chase-Landale, 1998; Levine, Garcia Coll, \& Oh, 1985). The threat to care-giving imposed by adolescent mothers' limited psychosocial resources may be buffered by a supportive family environment, partner, or professional (Schellenbach, Whitman, \& Borkowski, 1992). Social support may be a key to success when young mothers and their children do well in spite of major challenges.

\section{Social Support, Parenting, and Children's Development}

In comparison to older mothers who often turn to friends for help and information about child care, adolescents more often rely on their own mothers and other family members (Burke \& Liston, 1994; Musick, 1994; Schilmoeller \& Baranowski, 1985). Family support is associated with adolescent mothers' overall satisfaction with life (Unger \& Wandersman, 1988), and maternal reports of fewer concerns with daily living and financial matters. In contrast, living apart from related adults was the strongest risk factor associated with child maltreatment in Flanagan et al.'s (1995) study of adolescent mothers. Improvements to adolescent mothers' socioeconomic status by living with family may help explain improvements to their children's development.

Social support, whether provided by formal (e.g. health professionals) or informal (e.g. family, friends) sources has been related to adolescent motherchild interaction quality (von Windeguth \& Urbano, 1989) and confidence in providing infant care (Ruchala \& James, 1997). Indeed, social support that includes parenting education (such as parent training for infant care by 
Nicole Letourneau, C. B. Fedick, J. D. Willms, M. Stewart and K. White

professionals) may help compensate for adolescent mothers' often limited educational attainment. Indeed, educational attainment is associated with improvements in parenting and child development, regardless of maternal age (Sumner \& Spietz, 1994a) and may confound the observed impact of social support on older and adolescent mothers.

Support from an adolescent mother's mother enhanced interactions between adolescent mothers and their infants (Levine, Garcia Coll, \& Oh, 1985; Osofsky, Hann, \& Peebles, 1993). Adolescent mothers' perception of reliability and permanence in their relationships has been associated with successful adaptation to parenthood (Boyce, Kay, \& Uitti, 1988). Moreover, adolescent mothers may be more responsive to the effects of social support than older mothers (Schilmoeller, Baranowski, \& Higgins, 1991). Adolescent mothers living with their husbands or boyfriends has been associated with stronger social support, more positive child-rearing attitudes and mother-infant play interactions (Burke \& Liston, 1994; Field, Widmayer, Adler, \& et al., 1990), greater responsiveness to infants, and greater maternal psychological well-being (Roye \& Balk, 1996; Unger \& Wandersman, 1988), adjustment to parenting and favorable developmental outcomes for the infant (Kelly, 1995; Ruff, 1990; Samuels, Stockdale, \& Crase, 1994; Seymore, Frothingham, MacMillan, \& et al., 1990). In contrast, single parenthood and little support from a partner after a child's birth was associated with anger and punitive behavior by adolescent mothers toward their toddlers (Crockenberg, 1987).

\section{Anxiety and Hyperactivity.}

Adolescent mothers are more prone to anxiety and depression than older mothers and these symptoms may be reproduced by their children as both internalizing (e.g. anxiety, depression, and avoidance) and externalizing (e.g. hyperactivity) behaviors (Dumas, LaFreniere, \& Serketich, 1995; Shortt, Barrett, Dadds, \& Fox, 2001). Literature on anxiety and hyperactivity in young children is scarce while studies of older children (Jekielek, 1998; Leinonen, Solantaus, \& Punamaeki, 2003; Muris, Meesters, Schouten, \& Hoge, 2004) reveal that parenting is related to children's behavioral outcomes, including anxiety and hyperactivity. Parental behavior affects children via modeling which may be played out in gender-specific ways. Boys exposed to stressful, caregiving environments often respond to conflict with uncontrolled, or externalizing behaviors (e.g. hyperactivity, aggression), while girls respond through over controlled or internalizing behaviors (e.g. anxiety/depression) (Amato \& Rezac, 1993; Camara \& Resnick, 1988; Emery, 1982; Fainsilber-Katz \& Geottman, 1993; Long, Slater, Forehand, \& Fauber, 1987). Children's emotional and behavioral problems may be worsened when mothers' internalized problems, 
such as depression coexist with lack of social support from partner and friends (Sommer, Whitman, Borkowski, \& et al., 2000). Lack of partner support has been associated with deteriorations in both parent-child relationships and children's behavior (Amato \& Rezac, 1993; Grych \& Fincham, 1990; Peterson \& Zill, 1986). A larger social network size, including multiple sources of support (e.g. professional, family, friends, partner) and social ties, are significantly associated with diminished maternal stress (Camp, Holman, \& Ridgeway, 1993). Social ties to significant others are linkages through which child-rearing information can flow to affect adolescents' parenting behavior (Ruchala \& James, 1997; Stevens, 1988). Social support may help reduce both the incidence and impact of parental anxiety, depressive symptoms, and improve parenting, thereby reducing the incidence of emotional and behavioral problems in children.

The purpose of this study is to examine the impact, over time, of socialenvironmental characteristics that influence the development of anxiety and hyperactivity in children of adolescent and older mothers. Specifically, this study attempts to answer the research question: Comparing adolescent and older mothers, what are the effects of social support and parenting on children's anxiety and hyperactivity, controlling for maternal depressive symptomatology, maternal education, single parenting, socioeconomic status, and child gender? The hypotheses for this study are as follows:

- Children of mothers who were under the age of 19 (adolescent mothers) when the child was born will display higher levels of anxiety and hyperactivity than children of mothers who were older than 19 (older mothers) when the child was born.

- A sex effect on behavioral outcomes is anticipated, in that males of adolescent mothers will display higher levels of hyperactivity than will females of adolescent mothers, whereas females of adolescent mothers will display higher levels of anxiety than will males of adolescent mothers.

- The above hypotheses will be observed, even after taking into account parenting, social support, demographic, and control variables.

This research is underpinned by the widely recognized Child Health Assessment Model (Barnard, 1976; Sumner \& Spietz, 1994b) that describes the interaction 
Nicole Letourneau, C. B. Fedick, J. D. Willms, M. Stewart and K. White

between three potent factors that predict developmental outcomes in children. These interacting factors include characteristics of the environment (e.g. socioeconomic status, family structure, social support), the parent/caregiver (e.g. adolescent mother, maternal mental health and education), and the child (e.g. temperament). The interaction between these three factors determines children's health and developmental outcomes. In this study, the contributions of socialenvironmental and parenting characteristics to children's displays of anxiety and hyperactivity are examined.

\section{Method}

Data from the National Longitudinal Survey of Children and Youth (NLSCY), a survey launched in 1994 by Statistics Canada to track the development, health, and well-being of a nationally representative sample of children in Canada over time, was used in the current study. Four cycles of NLSCY data were available at the time of the current study: Cycle 1 (1994-95), Cycle 2 (1996-97), Cycle 3 (1998-99) and Cycle 4 (2000-01). All consenting participants in Statistics Canada surveys agree to secondary analysis of their data at enrollment using informed consent procedures (Statistics Canada, 1994-2001). The current study is based on children who were less than 24 months of age in Cycle 1 and participated in at least one subsequent cycle. Specifically, children between the ages of 0 and 24 months of age in Cycle 1 (1994-95) of the NLSCY were identified and followed in subsequent cycles, up to 96 months (8 years of age).

Many of the predictor variables used in this study were designed to evaluate only children under the age of 24 months while the outcome measures were designed to evaluate children 24 months of age and older. Therefore, information for the predictor variables had to be extracted from Cycle 1 data while information for the outcome measures had to be extracted from subsequent cycles.

The population of interest in this study was children whose mothers were 19 years of age or younger at the birth of the child; the sample for analysis included both teen and older mothers for comparative purposes. Additional selection criteria required that the person providing responses to survey items, the person most knowledgeable (PMK) was the biological mother of the child. Sample size was maximized by including children surveyed in Cycle 1 (for predictor variable information) and at least one subsequent cycle of the NLSCY (Cycle 2, 3, or 4) (for valid outcome variable information). All together, 3473 children were included in the sample for analysis, 143 whose mothers were 19 years of age or younger at the birth of the child and 3330 children whose mothers were over the 
Longitudinal Study of Social-environmental Predictors of Behaviour:

Children of Adolescent and Older Mothers Compared

age of 19. Table 1 details the cycle participation of the 3473 children selected from the NLSCY for this study.

Table 1

Number of Children Age 24 Months or Younger in Cycle 1

Participating in Two, Three or Four Cycles of the NLSCY

In Cycle 1 and ...

Number of Children

... one of Cycle 2, 3, or 4

361

(total of two cycles)

... one of Cycle 2, 3, or 4

801

(total of three cycles)

... one of Cycle 2, 3, or 4

2311

(total of four cycles)

\section{Behavioral Outcomes}

The behavioral outcome measures for this study, children's anxiety and hyperactivity, were derived from a series of sub-items reported in the NLSCY Behavior Scale, designed to assess aspects of behavior in children two years of age and older. The values of the sub-items had possible values of 1,2 or 3, where a score of 1 indicated a response by the PMK of "never or not true", a score of 2 indicated a response of "sometimes or somewhat true", and a score of 3 indicated a response of "often or very true" to a statement concerning the behavior of the child of the form "How often would you say that your child...?". Examples of these sub-items for anxiety include "...is too fearful or anxious?" and "...is worried?"; for hyperactivity, examples include "...is distractible or has trouble sticking to any activity?" and "...can't sit still or is restless or hyperactive?". Each behavioral outcome measure (anxiety and hyperactivity) was computed as the mean of the sub-item scores if the child had valid data on at least two of the construct sub-items. If the child was missing data on all or all 
Nicole Letourneau, C. B. Fedick, J. D. Willms, M. Stewart and K. White

but one of the construct sub-items, that behavioral outcome measure was computed as missing. The values of these behavioral outcome measures therefore range from 1 through 3, where higher scores indicate an increased presence of the behaviour in the child. Reliabilities for the behavioural outcomes in Cycle 1 are as follows: anxiety -0.59 and hyperactivity -0.80 (Statistics Canada, 1998).

\section{Predictors}

Adolescent motherhood. The predictor variable of interest in this study, whether the biological mother of the child was 19 years of age or younger at the time of birth of the child, is a dichotomous variable where mothers who were older than 19 at the birth of the child are coded as 0 and mothers who were 19 or younger are coded as 1 .

Social Support. The Social Support scale in the NLSCY (Statistics Canada, 1994-2001) is a shorter version of the Social Provisions Scale developed by Cutrona and Russell (1987), and is used to measure perceived support and the following components of social relationships: guidance, reliable alliance (the assurance that others can be counted on for practical help), and attachment. The scale is used to determine the level of social support received from family, friends, and others, and includes six items, each of which contain four response categories ranging from strongly disagree (1) to strongly agree (4). Of these six items, three were worded such that the responses to them needed to be reversecoded before being incorporated into the scale in order that higher scores indicated higher levels of social support in all six variables. Such a reversecoded item included the statement "If something went wrong, no one would help me", whereas an example of an item that did not require reverse coding was "I have friends and family who help me feel safe, secure and happy". In order that the lowest score value be zero, the value of the categories was reduced by 1 in calculating the score so that each item score actually ranged from 0 to 3 and the total scale score varied between 0 and 18, with higher scores indicating more social support. Factor analysis on the individual aspects indicated the presence of a single factor measuring global social support; as such, the individual aspects measuring social support were left from the analysis. The reliability for social support in Cycle 1 was 0.82 (Statistics Canada, 1998).

Parenting. Parenting was examined on three dimensions: (1) Positive Discipline, (2) Warm and Nurturing, and (3) Consistent. Ten items made up the scale for Positive Discipline (e.g. "How often do you have to discipline your child repeatedly for the same thing?" and "When your child breaks the rules or does things that he/she is not supposed to, how often do you calmly discuss the 
problem?"), 6 items made up Warm and Nurturing (e.g. "How often do you praise your child saying something like 'Good for you!' or 'What a nice thing you did!' or 'That's good going!'?" and "How often do you and your child talk or play with each other, focusing attention on each other for 5 minutes or more, just for fun?"), and 5 items made up Consistent (e.g. "When you give your child a command, what proportion of the time so you make sure that he/she does it?" and "When your child breaks the rules or does things that he/she is not supposed to, how often do you ignore it, do nothing?") (Sommer, Whitman, Borkowski, \& et al., 2000). Responses range from one to five with reverse coding of some questions, so that higher scores indicate more optimal parenting practices. The reliabilities of these dimensions in Cycle 1 have been calculated as 0.76, 0.80, and 0.66 , for positive discipline, warm and nurturing and consistent (Chao \& Willms, 2002).

Demographic and Control Variables. Demographic predictors known to affect children's behavioral outcomes were chosen to be included in the analysis. Maternal Education was measured as the total number of years of formal education of the mother; Single Parent Status was a dichotomous variable that included whether or not the child was being raised in a singleparent household, with those being raised by a single parent coded as 1 and those not being raised by a single parent coded as 0 . The Sex of the Child was reported by a dichotomous variable where females are coded 1 and males are coded 0 . SES was measured using questions specifically for the NLSCY, which resulted in five derived variables: PMK years of schooling, spouse years of schooling, PMK occupational status, spouse occupational status, and household income. The occupational variables used in the derivation of SES were modified versions of the scale developed by Pineo, Porter and McRoberts (1977) that groups occupations into 16 somewhat homogeneous categories and applies a logit transformation to express the 16 occupational categories on an interval scale. If no spouse was indicated, the primary caregiver's average over the three variables (years of schooling, occupation, and household income) was applied and imputed as the spouse's. The final SES composite was standardized to have a mean of 0 and a standard deviation of 1 for all families (Willms \& Shields, 1996). Finally, maternal depression was measured using the NLSCY scale, a shorter version of the Centre for Epidemiological Studies Depression Scale (CES-D) (Radloff, 1977). Comprised of 12 questions, this rating scale is used to measure the frequency of symptoms in the public at large. The occurrence and severity of symptoms associated with depression in the previous week are measured. Each of the 12 questions contains four response categories, ranging from 0 to 3 . The total score may vary between 0 and 36 , with higher scores indicating the presence of depressive symptoms. For the shortened version of the scale, all 12 items were retained because all 12 loading values met the 
Nicole Letourneau, C. B. Fedick, J. D. Willms, M. Stewart and K. White

scale, all 12 items were retained because all 12 loading values met the established threshold in the factor analysis. The Cronbach's alpha coefficient was 0.82 (Statistics Canada, 1994-2001).

Interaction Terms. Due to the differential impact of sex on the expression of internalizing (anxiety) and externalizing (hyperactivity) behaviors reported in the literature (Wakschlag et al., 2000), an interaction term was created to specifically examine these sex differences by multiplying the adolescent mother variable (where adolescent mothers are coded as 1) by Sex of Child (where females are coded as 1). Additional interaction terms were calculated to examine the differential impact of predictor and demographic variables (Positive Discipline, Warm and Nurturing, Consistent, Social Support, Maternal Education, SES, Single Parent Status, Sex of the Child and Maternal Depression) in combination with Adolescent Mother.

Analyses

Descriptive statistics were calculated to examine sample characteristics over time. Independent t-tests were conducted cross-sectionally to provide comparative data on sample characteristics. Hierarchical Linear Modeling (HLM) was used to model the data longitudinally, specifically to examine children's behavioral growth trajectories. HLM was used because when data are collected on the same children over multiple time points, the observations themselves are no longer independent, and normal regression analysis becomes inappropriate. Growth curve HLM takes into account the clustering of observations by estimating a single model that describes data at two levels: within-child and between-child (Raudenbush \& Bryk, 2002). Within-child differences, specified in the Level-1 model, summarize an observed pattern of an outcome variable across measurement occasions into a functional relationship with time. A typical trajectory can be specified as follows:

$$
\mathrm{Y}_{\mathrm{it}}=\beta_{0 \mathrm{i}}+\beta_{1 \mathrm{i}} \mathrm{X}_{\mathrm{it}}+\varepsilon_{\mathrm{it}}
$$

where $Y_{i t}$ represents an outcome score for the $i^{\text {th }}$ child at time $t, X_{i t}$ stands for each measurement occasion for the $\mathrm{i}^{\text {th }}$ child, $\beta_{0 \mathrm{i}}$ is the intercept of the underlying trajectory for the $i^{\text {th }}$ child, $\beta_{1 \mathrm{i}}$ is the slope of the underlying trajectory of the $\mathrm{i}^{\text {th }}$ child, and $\varepsilon_{i t}$ is the error term. Between-child differences are specified in the Level- 2 model, where the effects of variables on $\beta_{0 \mathrm{i}}$ and $\beta_{1 \mathrm{i}}$ are calculated using:

$$
\begin{aligned}
& \beta_{0 \mathrm{i}}=\gamma_{00 \mathrm{i}} Z_{1 \mathrm{i}}+\gamma_{01 \mathrm{i}} Z_{2 \mathrm{i}}+\ldots \mathrm{r}_{0 \mathrm{i}} \text { and } \\
& \beta_{1 \mathrm{i}}=\gamma_{10 \mathrm{i}} Z_{1 \mathrm{i}}+\gamma_{11 \mathrm{i}} Z_{2 \mathrm{i}}+\ldots \mathrm{r}_{0 \mathrm{i}}
\end{aligned}
$$

where $\gamma_{00}, \gamma_{01}$, etc. are coefficients denoting the effects of selected predictor variables, Z. In this analysis, one-tailed testing was used as enough evidence 
Longitudinal Study of Social-environmental Predictors of Behaviour:

Children of Adolescent and Older Mothers Compared

exists in the literature to hypothesize directional effects on the outcome variables.

Longitudinal sampling weights are typically used to adjust for a complex multistage sample design and non-response of the original cohort over time. However, these weights do not take into account the design effect of the survey so that variance estimates are still underestimated (Pfefferman \& Sverchkov, 2003). Moreover, it may be argued that if the specified model is correct, sampling will not induce bias in the unweighted estimators of the regression coefficients (Chambers \& Skinner, 2003). Further, as the goal of the study was to examine relationships and not to generalize to the Canadian population, longitudinal weights were not employed in the HLM procedures.

Three models were run to comprehensively explain the effects of being an adolescent mother on children's behavioral outcomes: the aim of Model 1 was to detect differences in anxiety and hyperactivity between children of adolescent and older mothers, while Model 2 investigated whether or not the sex of the child affected the trajectories of behavioral outcomes revealed by Model 1 . Model 3 sought to investigate potentially mediating effects of variables known to impact the maternal-child interactions and child development on the trajectories revealed by Model 1, including social support, parenting, maternal education, single parent status, SES, maternal depression and the sex of the child (Barnard, 1997; Beck, 1995; Letourneau, 2001; Wakschlag et al., 2000), as well as a set of interaction terms to examine the differential impact of predictor and demographic variables. Table 2 details each of the models.

\section{Findings}

Tables $3 \mathrm{a}$ and $3 \mathrm{~b}$ compare, for children of adolescent and older mothers, the first (earliest) valid value of predictor and demographic variables, and mean values of the two behavioral outcomes (anxiety and hyperactivity) by NLSCY survey cycle, respectively. Table 3a shows that children of adolescent mothers tend to come from mothers with less available social support and who display lower levels of warm and nurturing and consistent parenting, mothers who have less education and higher levels of depression, and single parent households and households with lower SES than children of older mothers. Table $3 \mathrm{~b}$ shows that mean anxiety increases and hyperactivity decreases over time for all children and that children of adolescent mothers have higher mean values on anxiety and hyperactivity than children of older mothers in Cycles 2 and 3 (Independent 
Table 2

Details of HLM Models 1 and 2.

\begin{tabular}{|c|c|c|}
\hline & Model 1 & Model 2 \\
\hline Level-1 Equation & $\mathrm{Y}=\beta_{0}+\beta_{1}($ Age $)+\mathrm{R}$ & $\mathrm{Y}=\beta_{0}+\beta_{1}($ Age $)$ \\
\hline Level-2 Equations & $\begin{array}{l}\beta_{0}=\gamma_{00}+\gamma_{01} \text { (Adolescent Mother) } \\
+\mu_{0} \\
\beta 1=\gamma 10+\gamma 11 \text { (Adolescent } \\
\text { mother) }+\mu 1\end{array}$ & 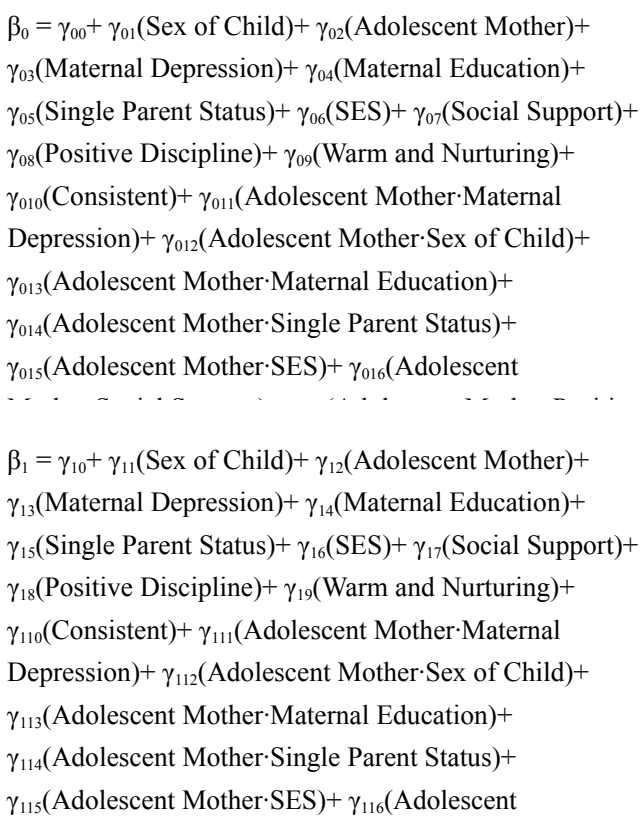 \\
\hline
\end{tabular}


Longitudinal Study of Social-enviornmental Predictors of Behaviour: Children of Adolescent and Older Mothers Compared
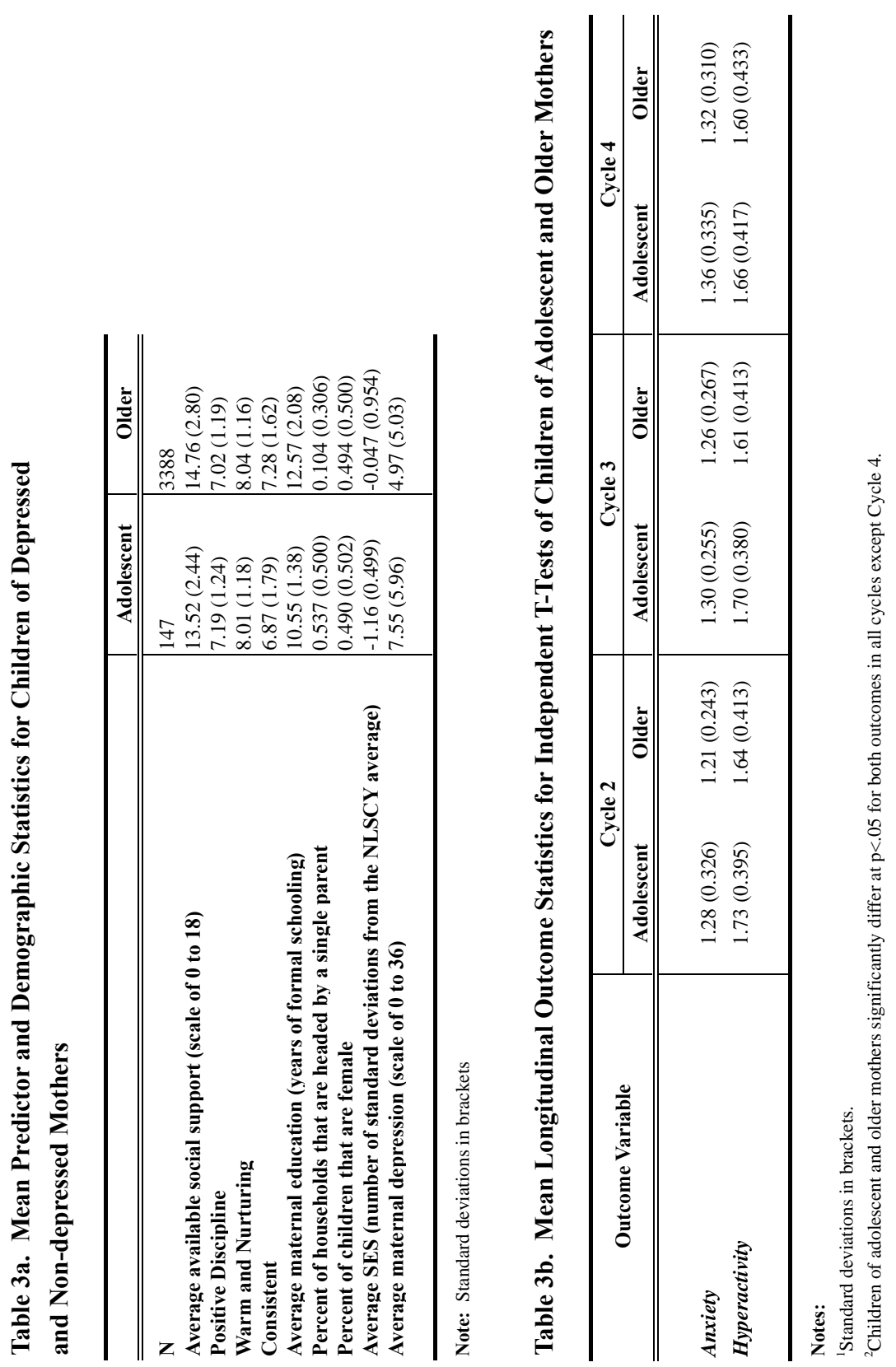
samples t-tests revealed no difference in mean anxiety or hyperactivity between children of adolescent and older mothers in Cycle 4).

HLM was used to examine the relationship between predictor and demographic variables and children's initial level (at age 2) and rate of change for each of the behavioral outcomes. Coefficients of each predictor or demographic variable report the effect of the variable (within two years after the time of birth on the child) on child's anxiety and hyperactivity levels from age 2 through 8.

Tables 4 through 6 report the effect of predictor and demographic variables on children's initial level (at age 2) and rate of change for each of the behavioral outcomes (anxiety and hyperactivity) as reported by HLM. Coefficients for each predictor or demographic variable report the effect of that variable (within two years after the time of birth on the child) on the child's anxiety and hyperactivity levels from age 2 through 8 .

Table 4 reports HLM results for Model 1 for each of the behavioral outcomes and indicates that children of adolescent mothers have higher initial levels of anxiety and hyperactivity than children of older mothers, and that anxiety increases over time while hyperactivity decreases over time at the same rate for children of both adolescent and older mothers. Figure 1 portrays the trajectories of anxiety and hyperactivity for children of adolescent and older mothers from 2 through 8 years of age.

Table 5 reports HLM results for Model 2 for each of the behavioral outcomes, when the sex of the child is taken into account. When the sex of the child is taken into account, children of adolescent and older mothers display the same patterns of anxiety levels from age 2 to age 8 . The sex of the child does have an effect on initial levels of hyperactivity, in that the effect of being an adolescent mother on initial level of hyperactivity is negated when the sex of the child is taken into account and female children display slightly lower initial levels of hyperactivity at age 2 . In addition, the sex of the child appears to affect the rate of change of hyperactivity from age 2 to age 8 in that hyperactivity in female children appears to decrease over time while that of male children remains the same; however, an interaction effect between the sex of the child and whether or not the child's mother was an adolescent when the child was born is revealed and results suggest that female children of adolescent mothers show a steeper decrease in hyperactivity levels than do female children of older mothers and male children of adolescent mothers show a steeper increase in hyperactivity levels than do male children of older mothers. Figure 2 portrays the trajectories of anxiety and hyperactivity for children of adolescent and older mothers from 2 through 8 years of age, when the sex of the child is taken into account. 
Longitudinal Study of Social-enviornmental Predictors of Behaviour: Children of Adolescent and Older Mothers Compared

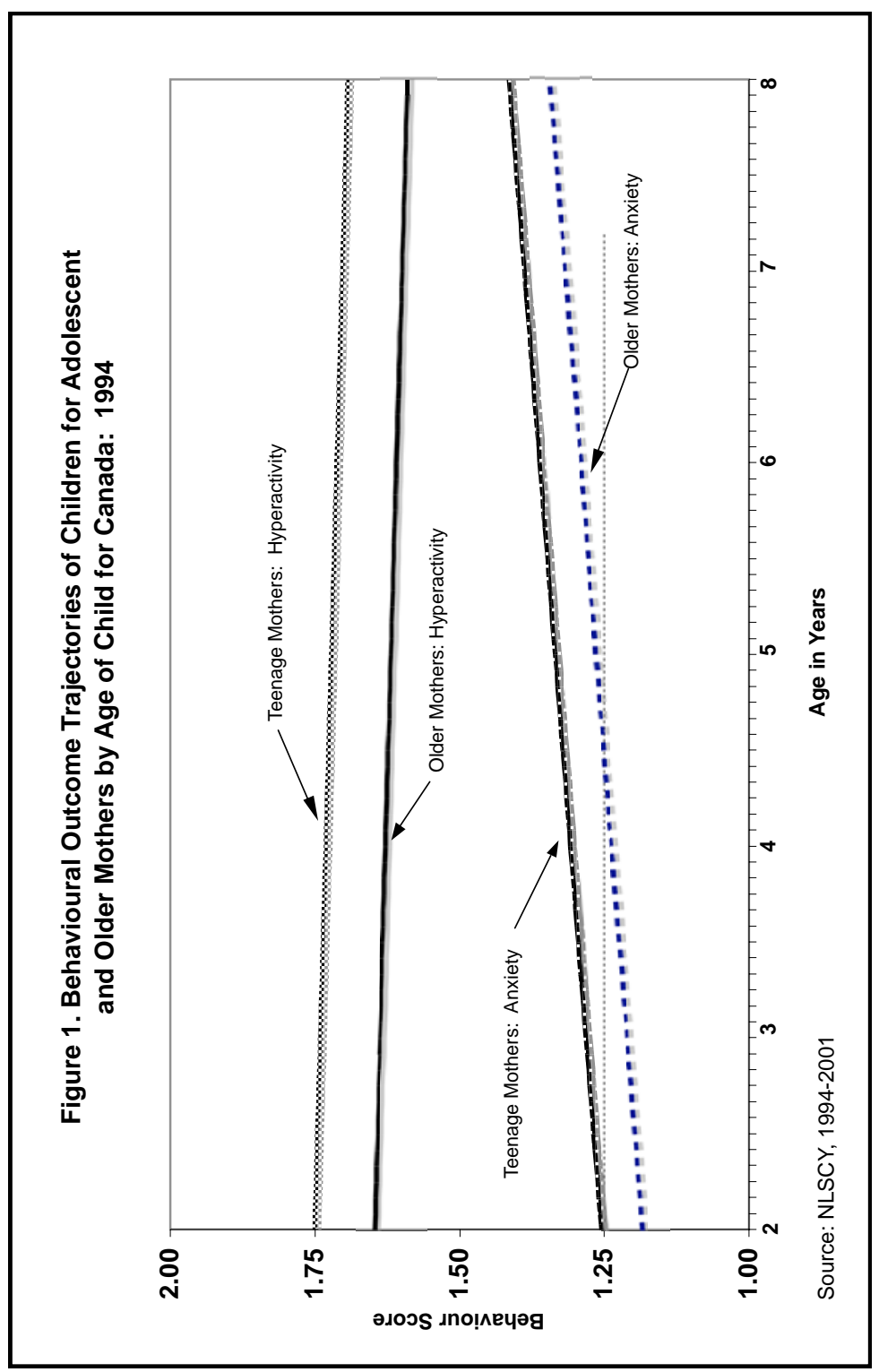


Nicole Letourneau, C. B. Fedick, J. D. Willms, M. Stewart and K. White

Table 4

Final Estimation of Fixed Effects

HLM Output for the Trajectory of Anxiety and Hyperactivity: Model 1

\begin{tabular}{lcc}
\hline \multicolumn{1}{c}{ Fixed Effect } & Anxiety & Hyperactivity \\
\hline \hline & & \\
Intercept (behavior at age 2), $\boldsymbol{\beta}_{0}$ & & \\
Intrcpt2, $\gamma_{00}$ & $\mathbf{1 . 1 8}(0.005)$ & $\mathbf{1 . 6 5}(0.008)$ \\
Adolescent Mother, $\gamma_{01}$ & $\mathbf{0 . 0 7 0}(0.032)$ & $\mathbf{0 . 1 0 3}(0.039)$ \\
Slope (change in behavior for one year of age), $\boldsymbol{\beta}_{1}$ & & \\
Intrcpt2, $\gamma_{10}$ & $\mathbf{0 . 0 2 7}(0.002)$ & $\mathbf{- 0 . 0 1 0}(0.002)$ \\
Adolescent Mother, $\gamma_{11}$ & $-0.006(0.010)$ & $-0.007(0.012)$ \\
& & \\
\hline
\end{tabular}

Notes:

${ }^{1}$ Standard errors in brackets.

${ }^{2}$ Coefficients in bold are significant at an alpha level of 0.05 (one-tailed).

Table 5

Final Estimation of Fixed Effects

HLM Output for the Trajectory of Anxiety and Hyperactivity: Model 2

\begin{tabular}{|c|c|c|}
\hline Fixed Effect & Anxiety & Hyperactivity \\
\hline \multicolumn{3}{|l|}{ Intercept (behavior at age 2), $\beta_{0}$} \\
\hline Intrcpt $2, \gamma_{00}$ & $1.18(0.007)$ & $1.69(0.012)$ \\
\hline Sex of Child, $\gamma_{01}$ & $0.005(0.010)$ & $\mathbf{- 0 . 0 8 1}(0.016)$ \\
\hline Adolescent Mother, $\gamma_{02}$ & $0.065(0.043)$ & $0.046(0.048)$ \\
\hline Adolescent Mother:Sex of Child, $\gamma_{03}$ & $0.012(0.064)$ & $0.119(0.078)$ \\
\hline \multicolumn{3}{|c|}{ Slope (change in behavior for one year of age), $\beta_{1}$} \\
\hline Intrcpt2, $\gamma_{10}$ & $\mathbf{0 . 0 2 7}(0.002)$ & $-0.003(0.003)$ \\
\hline Sex of Child, $\gamma_{11}$ & $-0.001(0.003)$ & $\mathbf{- 0 . 0 1 4}(0.004)$ \\
\hline Adolescent Mother, $\gamma_{12}$ & $-0.000(0.014)$ & $0.020(0.016)$ \\
\hline Adolescent Mother $\cdot$ Sex of Child, $\gamma_{13}$ & $-0.012(0.020)$ & $\mathbf{- 0 . 0 5 5}(0.022)$ \\
\hline
\end{tabular}

Notes:

${ }^{1}$ Standard errors in brackets.

${ }^{2}$ Coefficients in bold are significant at an alpha level of 0.05 (one-tailed).

${ }^{3}$ Of the tested interaction terms, only significant terms are listed. 
Longitudinal Study of Social-enviornmental Predictors of Behaviour: Children of Adolescent and Older Mothers Compared

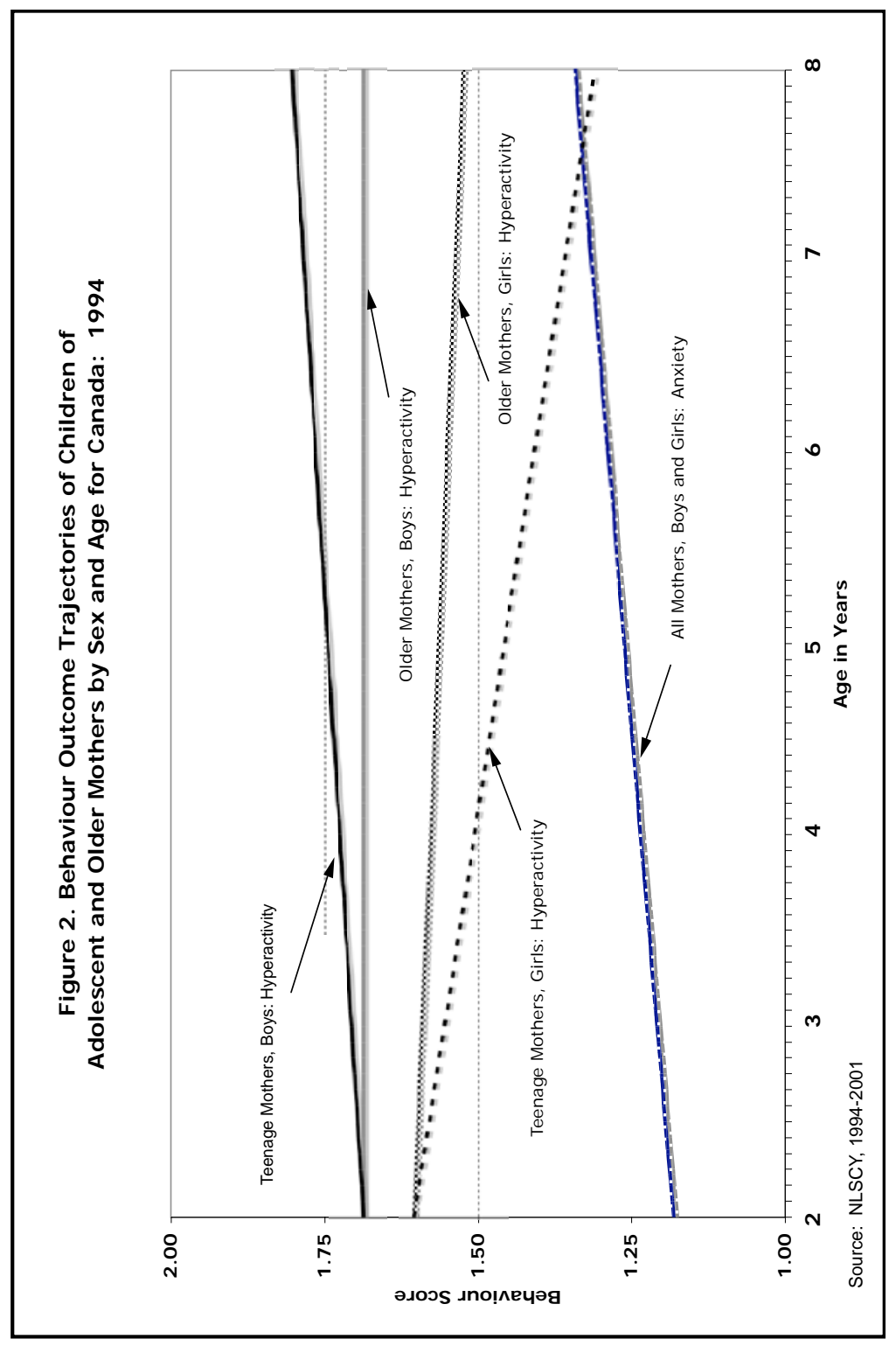


Table 6 reports HLM results for Model 3 for each of the behavioral outcomes when predictor, demographic, and control variables are controlled. Children of adolescent mothers display considerably higher initial levels of anxiety, and maternal depression is shown to slightly increase initial levels, whereas both positive discipline and, to a lesser extent, consistent parenting are shown to lower initial levels of anxiety. Significant interaction effects between being an adolescent mother and each of maternal education and warm and nurturing parenting suggest that for adolescent mothers, increased levels of education and warm and nurturing parenting may counteract the effects of being an adolescent mother by decreasing initial levels of their children's anxiety. In terms of the rate of change, anxiety levels for children of adolescent mothers decrease at a considerably steeper rate than do levels for children of older mothers, and a significant interaction effect between being an adolescent mother and being a single parent indicates that children of single, adolescent mothers show an even steeper decline. Variables shown to increase children's anxiety over time include positive discipline and consistent parenting (although these increases are very slight), and a significant interaction between adolescent motherhood and maternal education suggests that increased education for adolescent mothers increases anxiety in their children over time.

Finally, Table 6 shows that the negative effect of being an adolescent mother on children's initial hyperactivity is negated when other variables are controlled for. Positive discipline and, to a lesser extent, consistent parenting decrease initial levels of hyperactivity, as does higher SES, and a significant interaction between adolescent motherhood and warm and nurturing parenting suggests that adolescent mothers who are warm and nurturing towards their children may lower their children's initial levels of hyperactivity. Female children display lower initial levels of hyperactivity but a significant interaction between adolescent motherhood and the sex of the child indicates that females of adolescent mothers actually show higher initial levels of hyperactivity than male children of adolescents. Increased maternal depression also slightly increases initial levels of hyperactivity. In terms of the rate of change, hyperactivity decreases slightly over time for children of both adolescent and older mothers, but the decrease is slightly steeper for female children of adolescent mothers. Social support makes the decrease minutely steeper, while positive discipline and single parent status each act to reverse the direction of change and increase hyperactivity over time. 
Longitudinal Study of Social-enviornmental Predictors of Behaviour: Children of Adolescent and Older Mothers Compared

Table 6

Final Estimation of Fixed Effects

HLM Output for the Trajectory of Anxiety and Hyperactivity for Model 3

\begin{tabular}{|c|c|c|}
\hline Fixed Effect & Anxiety & Hyperactivity \\
\hline \multicolumn{3}{|l|}{ Intercept (behavior at age 2), $\beta_{0}$} \\
\hline Intrcpt2, $\gamma_{00}$ & $1.55(0.071)$ & $2.69(0.104)$ \\
\hline Adolescent Mother, $\gamma_{02}$ & $1.48(0.478)$ & $0.475(0.492)$ \\
\hline Social Support, $\gamma_{07}$ & $-0.000(0.002)$ & $0.004(0.003)$ \\
\hline Positive Discipline, $\gamma_{08}$ & $\mathbf{- 0 . 0 5 8}(0.005)$ & $\mathbf{- 0 . 1 4 5}(0.007)$ \\
\hline Warm and Nurturing, $\gamma_{09}$ & $0.002(0.004)$ & $-0.003(0.007)$ \\
\hline Consistent, $\gamma_{010}$ & $\mathbf{- 0 . 0 0 9}(0.003)$ & $\mathbf{- 0 . 0 1 4}(0.005)$ \\
\hline Maternal Education, $\gamma_{04}$ & $0.006(0.004)$ & $0.004(0.006)$ \\
\hline Single Parent Status, $\gamma_{05}$ & $-0.007(0.018)$ & $-0.027(0.028)$ \\
\hline Sex of Child, $\gamma_{01}$ & $0.015(0.009)$ & $\mathbf{- 0 . 0 5 8}(0.015)$ \\
\hline SES, $\gamma_{06}$ & $-0.010(0.009)$ & $\mathbf{- 0 . 0 4 3}(0.013)$ \\
\hline Maternal Depression, $\gamma_{03}$ & $\mathbf{0 . 0 0 5}(0.001)$ & $\mathbf{0 . 0 0 6}(0.002)$ \\
\hline Adolescent Mother-Sex of Child, $\gamma_{012}$ & & $\mathbf{0 . 1 7 7}(0.070)$ \\
\hline Adolescent Mother·Maternal Education, $\gamma_{013}$ & $\mathbf{- 0 . 0 7 3}(0.031)$ & \\
\hline Adolescent Mother $\cdot$ Warm and Nurturing, $\gamma_{018}$ & $\mathbf{- 0 . 0 5 7}(0.033)$ & $\mathbf{- 0 . 0 7 0}(0.033)$ \\
\hline \multicolumn{3}{|l|}{ Slope (change in behavior for one year of age), $\beta_{1}$} \\
\hline Intrcpt2, $\gamma_{10}$ & $\mathbf{- 0 . 0 4 4}(0.023)$ & $\mathbf{- 0 . 0 9 9}(0.029)$ \\
\hline Adolescent Mother, $\gamma_{12}$ & $\mathbf{- 0 . 5 0 0}(0.176)$ & $-0.162(0.170)$ \\
\hline Social Support, $\gamma_{17}$ & $0.000(0.001)$ & $\mathbf{- 0 . 0 0 1}(0.001)$ \\
\hline Positive Discipline, $\gamma_{18}$ & $\mathbf{0 . 0 0 7}(0.001)$ & $\mathbf{0 . 0 1 7}(0.002)$ \\
\hline Warm and Nurturing, $\gamma_{19}$ & $-0.000(0.001)$ & $-0.001(0.002)$ \\
\hline Consistent, $\gamma_{110}$ & $\mathbf{0 . 0 0 2}(0.001)$ & $0.001(0.001)$ \\
\hline Maternal Education, $\gamma_{14}$ & $0.000(0.001)$ & $-0.001(0.002)$ \\
\hline Single Parent Status, $\gamma_{15}$ & $0.002(0.006)$ & $\mathbf{0 . 0 1 8}(0.008)$ \\
\hline Sex of Child, $\gamma_{11}$ & $-0.002(0.003)$ & $\mathbf{- 0 . 0 1 7}(0.004)$ \\
\hline SES, $\gamma_{16}$ & $-0.001(0.003)$ & $-0.003(0.004)$ \\
\hline Maternal Depression, $\gamma_{13}$ & $0.000(0.000)$ & $0.000(0.000)$ \\
\hline Adolescent Mother:Sex of Child, $\gamma_{112}$ & & $\mathbf{- 0 . 0 5 5}(0.022)$ \\
\hline Adolescent Mother-Maternal Education, $\gamma_{113}$ & $\mathbf{0 . 0 2 5}(0.013)$ & \\
\hline Adolescent Mother-Single Parent Status, $\gamma_{114}$ & $\mathbf{- 0 . 0 4 6}(0.023)$ & \\
\hline
\end{tabular}


Nicole Letourneau, C. B. Fedick, J. D. Willms, M. Stewart and K. White

\section{Discussion}

The first hypothesis was supported in that children of adolescent mothers display higher initial levels of anxiety and hyperactivity than children of older mothers and the difference between the two groups of children remains constant over time. The second hypothesis that a sex effect on behavioral outcomes of adolescent mothers would be observed was partially supported. While no sex differences were observed between children of adolescent and older mothers on the anxiety outcome initially or over time, females of adolescent mothers were significantly less hyperactive than males at age two and over time. This finding agrees with the other literature on hyperactivity (Amato \& Rezac, 1993; Camara \& Resnick, 1988; Emery, 1982; Fainsilber-Katz \& Geottman, 1993; Long, Slater, Forehand, \& Fauber, 1987). The third hypothesis that children of adolescent mothers will display higher levels of anxiety and hyperactivity, even after taking into account parenting, social support, demographic, control variables and interaction terms was partially supported. While adolescent mothers' children were more anxious at age two and over time than children of older mothers, hyperactivity did not present the same pattern.

Maternal education appeared to decrease initial levels of anxiety in adolescents' children at age two as did maternal reports of being more warm and nurturing. However, over time, maternal education predicted an increase in adolescents' children's anxiety and single parent status reduced adolescent children's anxiety. It may be that the increased stress, time demands, and daily hassles associated with ongoing school attendance while raising a small child produces behavioural impacts in adolescents' children. While social support could function to reduce the stresses associated with school attendance, the interaction between social support and adolescent motherhood did not produce significant results for either anxiety or hyperactivity. Moreover, initial levels of hyperactivity were higher for females of adolescent mothers, in contrast to that expected. However, the rate of change for females is steeper, suggesting a more rapid return to normal levels than similarly affected males. These unexpected findings deserve further exploration.

While the social support variable was significant in one of the predictive models, it did not produce the expected effects overall. Perhaps the abbreviated version used in this study inadequately captures the intended elements of social relationships that are theorized to reduce stress and enhance coping with parenthood. Alternatively, interviewed parents may not interpret social support aimed at assisting them with parenting as fitting into the items that measure social support in this study (i.e. guidance, reliable alliance, attachment). Indeed, the instrument items address aspects of social support generally, and do not 
Longitudinal Study of Social-environmental Predictors of Behaviour:

Children of Adolescent and Older Mothers Compared

explicitly link social support to parenting support. In this case, parenting variables may confound the observed effect of social support on children's development and reduce the observed impact of social support. This possibility deserves exploration with the use of interaction terms in subsequent analysis.

The fixed effects coefficients are larger for adolescent mothers than for the other variables, suggesting a greater impact of adolescent motherhood on anxiety and hyperactivity than the other variables. However, in both groups, positive discipline and consistent parenting reduced and maternal depression increased children's reported level of anxiety and hyperactivity at age two. Moreover, positive discipline produced a significant positive impact on anxiety and hyperactivity over time while consistent parenting produced significant positive impacts on anxiety over time. These robust relationships between parenting characteristics and children's anxiety and hyperactivity are promising and suggest that all children could benefit from more optimal parent-child relationships and community-level interventions to promote optimal parenting.

In conclusion, HLM was used to explore the relationship between adolescent motherhood and sociodemographic variables on children's anxiety and hyperactivity outcomes. While adolescent motherhood does play a significant role in children's outcomes, it may be that additional parenting and mental health variables are at least as important in predicting children's outcomes. These findings may provide direction for universal community-based interventions to support families and children's development.

\section{Acknowledgement:}

Paper presented at the Conference of the Federation of Canadian Demographers on Longitudinal Studies and Demographic Challenges of the 21st Century Université de Montréal, 18-19 November 2005

\section{References:}

Amato, P. R., \& Rezac, S., J. (1993). Contact with non-resident parents, interparental conflict, and children's behaviour. Journal of Family Issues, 15, 191-207.

Barbour, N., Richardson, R., \& Bubenzer, D. (1995). Adolescent mothers and parenting stress: Comparisons with normative and later age mothers. Paper presented at the Biennial Society for Research in Child Development Meeting, Indianapolis, Indiana. 
Nicole Letourneau, C. B. Fedick, J. D. Willms, M. Stewart and K. White

Barnard, K. (1976). NCAST II Learners' Manual. Seattle: NCAST Publications.

Barnard, K. (1997). Influencing parent-child interactions for children at risk. In M. J. Guralnick (Ed.), The effectiveness of early interventions. (pp. 99126). Toronto: Paul Brooks.

Beck, C. T. (1995). The effects of postpartum depression on maternal-infant interaction: a meta-analysis. Nursing Research, 44(5), 298-304.

Belsky, J. (1984). The determinants of parenting: A process model. Child Development, 55, 83-96.

Boyce, W., Kay, M., \& Uitti, C. (1988). The taxonomy of social support: An ethnographic analysis among adolescent mothers. Soc Sci Med, 26, 10791085.

Buchholz, E., \& Korn-Bursztyn, C. (1993). Children of adolescent mothers: Are they at risk for abuse? Adolescence, 28, 361-382.

Burke, P., \& Liston, W. (1994). Adolescent mothers' perceptions of social support and the impact of parenting on their lives. Pediatric Nursing, 20, 593-599.

Camara, K. A., \& Resnick, G. (1988). Interparental conflict and cooperation: Factors moderating children's post-divorce adjustment. In E. M. Heatherington \& J. D. Arasteh (Eds.), Impact of Divorce, Single Parenting, and Stepparenting on Children (pp. 165-195): Lawrence Erlbaum.

Camp, B., Holman, S., \& Ridgeway, E. (1993). The relationship between social support and stress in adolescent mothers. Journal of Developmental and Behavioral Pediatrics, 14, 369-374.

Chambers, R., \& Skinner, C. (Eds.). (2003). Analysis of Survey Data. Southampton, UK: John Wiley \& Sons.

Chao, R. K., \& Willms, J. D. (2002). The effects of parenting practices on children's outcomes. In J. D. Willms (Ed.), Vulnerable Children: Findings from Canada's National Longitudinal Survey of Children and Youth (pp. 149-165). Edmonton: University of Alberta Press. 
Longitudinal Study of Social-environmental Predictors of Behaviour:

Children of Adolescent and Older Mothers Compared

Crockenberg, S. (1987). Predictors and correlates of anger toward and punitive control of toddlers by adolescent mothers. Child Development, 58, 964975.

Cutrona, C., \& Russell, D. (1987). The provisions of social relationships and adaptation to stress. In W. Jones \& D. P. (eds.) (Eds.), Advances in Personal Relationships (Vol. 1, pp. 37-67). Greenwich, CT: JAI Press.

Dumas, J. E., LaFreniere, P. J., \& Serketich, W. J. (1995). "Balance of power": A transactional analysis of control in mother-child dyads involving socially competent, aggressive, and anxious children. Journal of Abnormal Psychology, 104(1), 104-113.

East, P. L., \& Felice, M. E. (1990). Outcomes and parent-child relationships of former adolescent mothers and their 12-year old children. Journal of Developmental and Behavioural Pediatrics, 11, 175-183.

Emery, R. E. (1982). Interparental conflict and the children of discord and divorce. Psychological Bulletin, 92, 310-330.

Fainsilber-Katz, L., \& Geottman, J. M. (1993). Patterns of marital conflict predict children's internalizing and expernalizing behaviours. Developmental Psychology, 29, 940-950.

Field, T., Widmayer, S., Adler, S., \& et al. (1990). Teenage parenting in different cultures, family constellations and caregiving environments: Effects on infant development. Infant Mental Health Journal, 11, 158174.

Flanagan, P., Garcia Coll, C., Andreozzi, L., \& al., e. (1995). Predicting maltreatment of children of teenage mothers. Archives of Pediatrics and Adolescent Medicine, 149, 451-455.

Garrett, S., \& Tidwell, R. (1999). Differences between adolescent mothers and non-mothers: An interview study. Adolescence, 34(133), 91-105.

Grych, J. H., \& Fincham, F. D. (1990). Marital conflict and children's adjustments: A cognitive contextual framework. Psychological Bulletin, 108, 267-290.

Halpern, R. (1993). Poverty and infant development. In C. Zennah (Ed.), Handbook of Infant Mental Health. (pp. 73-86). New York, NY: Guildford Press. 
Nicole Letourneau, C. B. Fedick, J. D. Willms, M. Stewart and K. White

Herrmann, M. M., Van Cleve, L., \& Levison, L. (1998). Parenting competence, social support, and self-esteem in teen mothers case managed by public health nurses. Public Health Nursing, 15(432-439).

Jekielek, S. M. (1998). Parental conflict, marital disruption and children's emotional well-being. Social Forces, 76(3), 905-935.

Kelly, L. (1995). Adolescent mothers: What factors relate to preventive health care sought for their infants? Journal of Pediatric Nursing, 10, 5-113.

Klein, H., \& Cordell, A. (1987). The adolescent as mother: Early risk identification. Journal of Youth and Adolescence, 16(1), 47-58.

Leinonen, J. A., Solantaus, T. S., \& Punamaeki, R.-L. (2003). Parental mental health and children's adjustment: The quality of marital interaction and parenting as mediating factors. Journal of Child Psychology and Psychiatry \& Allied Disciplines, 44(2), 227-241.

Letourneau, N. (2001). Improving adolescent parent-infant interactions: a pilot study. Journal of Pediatric Nursing, 16(1), 53-62.

Levine-Coley, R., \& Chase-Landale, P. (1998). Adolescent pregnancy and parenthood: Recent evidence and future directions. American Psychologist, 53, 152-166.

Levine, L., Garcia Coll, C., \& Oh, W. (1985). Determinants of mother-infant interaction in adolescent mothers. Pediatrics, 75, 23-29.

Long, N., Slater, E., Forehand, R., \& Fauber, R. (1987). Self-perceived and independently observed competence of young adolescents as a function of parental marital conflict and recent divorce. Journal of Abnormal Child Psychology, 15, 15-27.

Muris, P., Meesters, C., Schouten, E., \& Hoge, E. (2004). Effects of Perceived Control on the Relationship Between Perceived Parental Rearing Behaviors and Symptoms of Anxiety and Depression in Nonclinical Preadolescents. Journal of Youth and Adolescence, 33(1), 51-58.

Musick, J. (1994). Grandmothers and grandmothers-to-be: Effects on adolescent mothers and adolescent mothering. Infants and Young Children, 6, 1-9. 
Longitudinal Study of Social-environmental Predictors of Behaviour:

Children of Adolescent and Older Mothers Compared

Office of Juvenile Justice and Delinquency Prevention (OJJDP. Guide for implementing the comprehensive strategy for serious, violent, and chronic juvenile offenders.: U.S. Department of Justice, Office of Juvenile Justice and Delinquency Prevention, Washington DC.

Osofsky, J., Hann, D., \& Peebles, C. (1993). Adolescent parenthood: Risks and opportunities for mothers and infants. In C. Zeanah (Ed.), Handbook of Infant Mental Health. (pp. 106-119). New York, NY: Guilford Press.

Osofsky, J., Wewers, S., Hann, D. M., \& Fick, A. (1993). Children's exposure to chronic communtity vioence: What are we doing to our children? Psychiatry, 56, 36-45.

Passino, A., Whitman, T., Borkowski, J., \& et al. (1993). Personal adjustment during pregnancy and adolescent parenting. Adolescence, 28(109), 97122.

Peterson, J. L., \& Zill, N. (1986). Marital Disruption, parent-child relationships, and behavior problems in children. Journal of Marriage and the Family, 49, 295-307.

Pfefferman, D., \& Sverchkov, M. (2003). Fitting generalized linear models under informative sampling. In R. Chambers \& C. Skinner (Eds.), Analysis of Survey Data (pp. 175-195). Southampton, UK: John Wiley \& Sons.

Pineo, P. C., Porter, J., \& McRoberts, H. A. (1977). The 1971 Census and the socioeconomic classification of occupations. Canadian Review of Sociology and Anthropology, 14, 91-102.

Radloff, L. S. (1977). The CES-D Scale: A self-report depression scale for research in the general population. Applied Psychological Measurement, $1(3), 385-401$.

Raudenbush, S., \& Bryk, A. (2002). Hierarchical linear models: Applications and data analysis methods. (2nd ed.). Thousand Oaks, CA: Sage.

Roye, C., \& Balk, S. (1996). The relationship between partner support to outcomes for teenage mothers and their children: A review. Journal of Adolescent Health, 19, 86-93.

CSP 2007; 34.1: 1-27 
Nicole Letourneau, C. B. Fedick, J. D. Willms, M. Stewart and K. White

Ruchala, P., \& James, D. (1997). Social support, knowledge of infant development, and maternal confidence among adolescent and adult mothers. Journal of Obstetric, Gynecologic, and Neonatal Nursing, 26, 685-689.

Ruff, C. (1990). Adolescent mothering: Assessing their parenting capabilities and their health education needs. Journal of National Black Nurses Assocation, 4, 55-61.

Samuels, V., Stockdale, D., \& Crase, S. (1994). Adolescent mothers' adjustment to parenting. Adolescence, 17, 427-443.

Schellenbach, C., Whitman, T., \& Borkowski, J. (1992). Towards an integrative model of adolescent parenting. Human Development, 35, 81-99.

Schilmoeller, G., \& Baranowski, M. (1985). Childrearing of firstborns by adolescent and older mothers. Adolescence, 20, 805-822.

Schilmoeller, G., Baranowski, M., \& Higgins, B. (1991). Long-term support and personal adjustment of adolescent and older mothers. Adolescence, 26, 787-797.

Seymore, C., Frothingham, T., MacMillan, J., \& et al. (1990). Child development knowledge, childrearing attitudes, and social support among first- and second-time adolescent mothers. Journal of Adolescent Health Care, 11, 343-350.

Shortt, A., Barrett, P., Dadds, M., \& Fox, T. (2001). The influence of family and experimental contest on cognition in anxious children. Journal of Abnormal Child Psychology, 29(6), 585-596.

Sommer, K., Whitman, T., Borkowski, J., \& et al. (2000). Prenatal and maternal predictors of cognitive and emotional delays in children of adolescent mothers. Adolescence, 35, 87-112.

Statistics Canada. (1994-2001). National Longitudinal Survey of Children and Youth. Ottawa, ON: Government of Canada.

Statistics Canada. (1998). National Longitudinal Survey of Children: Data Dictionary for Cycle 1. Ottawa, ON: Statistics Canada and Human Resources Development Canada. 
Longitudinal Study of Social-environmental Predictors of Behaviour:

Children of Adolescent and Older Mothers Compared

Stevens, J. (1988). Social support, locus of control, and parenting in three lowincome groups of mothers: Black teenagers, black adults, and white adults. Child Development, 59, 635-642.

Sumner, G., \& Spietz, A. (1994a). NCAST caregiver/parent child interaction feeding manual. Seattle, WA: NCAST Publications.

Sumner, G., \& Spietz, A. (1994b). NCAST caregiver/parent child interaction teaching manual. Seattle, WA: NCAST Publications.

Turner, R., Grindstaff, C., \& Phillips, N. (1990). Social support and outcome in teenage pregnancy. Journal of Health and Social Behavior, 31, 43-57.

Unger, D., \& Wandersman, L. (1988). The relation of family and partner support to the adjustment of adolescent mothers. Child Development, 59, 10561060 .

von Windeguth, B., \& Urbano, R. (1989). Teenagers and the mothering experience. Pediatric Nursing, 15, 517-520.

Wakschlag, L. S., Gordon, R. A., Lahey, B. B., Loeber, R., Green, S. M., \& Leventhal, B. L. (2000). Maternal age at first birth and boys' risk for conduct disorder. Journal of Research on Adolescence, 10(4), 417-441.

Willms, J. D., \& Shields, M. (1996). A measure of socioeconomic status for the National Longitudinal Study of Children: Report prepared for the Canadian National Longitudinal Study of Children. 